\title{
“FrONTERA DE SAL”, ENGARCE PARA UN TRÍPTICO DE LA IDENTIDAD MIGRANTE EN LA NARRATIVA DE NADia Villafuerte
}

\section{"Frontera de sal", the Frame For a Triptych of Migrant Identity in Nadia VILLAFUERTE'S Fiction}

\author{
Norma Angélica Cuevas Velasco*
}

DOI: http://dx.doi.org/10.29043/liminar.v19i2.845

\begin{abstract}
Resumen: Este artículo propone leer los dos libros de cuentos y la novela de Nadia Villafuerte como una summa narrativa, como un tríptico que en su composición engarza un relato, "Frontera de sal", que aparece en los dos primeros volúmenes y que es recuperado, ensanchado en su forma y en su estilo, en el cierre de la novela Por el lado salvaje. Desde la perspectiva de los estudios latinoamericanistas, particularmente desde la propuesta de Antonio Cornejo Polar, se identifican algunos elementos textuales y discursivos que especifican los modos de subjetivación de los personajes migrantes, cuyas visión, experiencia y voz tejen lo que podría ser una poética fronteriza estilizada no desde la perspectiva de un narrador omnisciente, sino desde la enunciación del propio migrante, que es un sujeto multicultural instalado en la línea de dos espacios culturales y políticos diferentes entre los cuales su identidad va acentuando la heterogeneidad que los define.
\end{abstract}

Palabras clave: Nadia Villafuerte, novela mexicana, migrantes, multiculturalidad, hibridación discursiva.

Abstract: This article examines two short storybooks and a novel by Nadia Villafuerte as a summa narrativa, like a triptych that in its composition incorporates a story, "Frontera de sal", which appears in the first two volumes and is brought back and extended in its form and style by the end of the novel Por el lado salvaje. From the LatinAmerican studies perspective, particularly from Antonio Cornejo-Polar's proposal, some textual and discursive elements are identified that specify the ways migrant characters are subjectivized, whose vision, experience, and voice weave what could be a border poetic, stylized not from the perspective of an omniscient narrator, but from migrants' own declarations, who are multicultural subjects straddling a line of two different political and cultural spaces, where their identity accentuates the heterogeneity that defines them.

Key words: Nadia Villafuerte, Mexican novel, migrants, multicultural, discursive hybridity.

\footnotetext{
* Norma Angélica Cuevas Velasco. Doctora en Literatura con énfasis en teoría literaria por la Universidad Autónoma Metropolitana, México. Profesora-investigadora en el Instituto de Investigaciones LingüísticoLiterarias de la Universidad Veracruzana, México. Temas de especialización: teoría literaria. Correo electrónico: ncuevas@uv.mx. ORCID: https://orcid.org/0000-0002-3922-1770
}

Enviado a dictamen: 21 de septiembre de 2020 Aceptación: 16 de febrero de 2021 
Una autora que es una pluma, que es una voz, que existe

L a revista Literal. Latin American Voices publicó, en 2016, el ensayo "100 protagonistas de la generación inexistente. Narradores mexicanos nacidos entre 1970 y 1979", en el que su autor, Jaime Mesa, además de integrar una nómina de escritores de novela y cuento - y sus alrededores genéricos-, registra puntualmente los títulos en circulación, incluidos los de su propia autoría. Los sellos editoriales son muy diversos: figuran desde editoriales con reconocimiento internacional hasta aquellas que se mueven (o se conocen, o se pueden adquirir) solo en librerías ubicadas en regiones específicas del mercado nacional.

Frente a la propuesta de Mesa (2016), conviene tener presentes los excursos publicados, en distintos sitios electrónicos, por Víctor Santana, Tryno Maldonado y Heriberto Yépez, quienes ponen en duda la tesis y los argumentos de Mesa y coinciden en afirmar que se trata de una lista en la que no están todos los que son ni son todos los que están, que más que una generación inexistente, la inexistente es la crítica sobre su obra. La polémica puede seguirse en las redes sociales de estos escritores, en sus blogs, en sus TL y en portales de la web, como Anaquel y Horizontal, y es, sin duda, interesante y digna de tomarse en cuenta; sin embargo, en este artículo se busca agudizar otra mirada que ninguno de los cuatro escritores referidos atiende: me refiero a la minoría de autoras en ese listado y a la escasa representación de la región sur en el campo literario mexicano actual.

Al margen de los posibles (e incluso válidos) argumentos de que toda lista siempre es incompleta, o que se construye con la intención de homogeneizar aquello que nace y se sostiene en la diversidad, bien vale la pena atender ese catálogo de títulos y autores e indagar en los textos que hoy, por decirlo de alguna manera, soporten la relectura. Entre esa labor de Mesa y los días que enfrentamos debido al confinamiento sanitario por la presencia del Sars-CoV-2 en el mundo, median siete años, los suficientes para hacer, al menos, una cala que nos permita sopesar la incidencia de esas obras en nuestra visión actual de la literatura, y del mundo. ¿De qué van los contenidos temáticos de esas obras? ¿A quién buscan hablarle? ¿Leyendo esas obras encontraría el lector respuestas a la realidad que hoy enfrenta? ¿De qué recursos estilísticos y poéticos se valen para contar sus historias? ¿Sus obran son respuesta a la moda impuesta por las diferentes instituciones que intervienen en el sistema literario? ¿Hay en sus narraciones interés genuino por señalar realidades que solo llevándolas a la ficción se vuelven socialmente visibles para dejar de ser únicamente incómodas? Las interrogantes pueden ser inagotables.

El mote de "la generación inexistente", se adivinará, contiene una paradoja, como la hay en la expresión "minificción", que reclama no fijar la atención en la brevedad de sus formas. No existe pero es. La "generación inexistente" — así nombrada por destacar entre ellos la usencia del claro deseo de pertenencia a un grupo-, involucra a hombres y a mujeres con un proyecto profesional fincado en el trabajo intelectual de la creación literaria, de la escritura crítica y de los procesos editoriales.

La "generación inexistente" nace en un contexto político y económico no de crisis, sino de permanencia de la crisis; en consecuencia sabe que no es suficiente con salir a buscar los apoyos para el trabajo intelectual, sino que hay que trabajar primero en generar las condiciones para que tales recursos existan. Son escritores y algo (más bien mucho) tienen de activistas: son plumas, pero también, y sobre todo, son voces que buscan involucrarse en el diseño de las políticas públicas o, cuando menos, atenderlas exitosamente. Los escritores de esta generación tienen experiencia en la participación por recursos públicos que les permitan realizar su labor de manera profesional: concursan en convocatorias y pelean lugares al lado de escritores que les llevan ventaja en años (diez, veinte o más) y en producción (en relaciones de amistad y colaboración con los creadores consagrados, también); la gran mayoría de estos aún jóvenes creadores ha sido beneficiada con alguna beca de la Fundación para las Letras Mexicanas, del Fondo Nacional para la Cultura y las Artes (FONCA), de la Secretaría de Cultura de su estado de origen o residencia, 
o ha pasado por la Sociedad General de Escritores de México (SOGEM). No todos alcanzan beca y esta no dura para siempre, así que también se distinguen, los pertenecientes a esta generación, por la diversificación de sus perfiles y su interés en los procesos editoriales, incluido el trabajo de la traducción, que llega a ser en algunos casos su asidero no necesariamente de especialización sino de manutención.

Entre los nacidos en los setenta destaca el grupo de escritores que se "reconcilia" con la Academia y estudia posgrados (nacionales o extranjeros), y hasta adquiere, mediante concurso (o no), plaza de tiempo completo en esta o aquella institución de educación superior, sea pública o privada. El desplazamiento, cuando no la inmigración nacional o internacional, es otro elemento que los agrupa. Su escritura está ligada a la comunicación y al periodismo.

Más que seguir un debate sobre la denominación de los narradores mexicanos nacidos en los años setenta, me interesa señalar, como adelanté, un par de asuntos que no deja de ser inquietante: en el grupo de los cien narradores, solo se registra a 21 mujeres, de las cuales más de la mitad nacieron en la Ciudad de México y el resto se reparte entre el Bajío y el norte del país. El sur está representado únicamente con dos narradoras: Iris García (Acapulco, Guerrero, 1977) y Nadia Villafuerte (Tuxtla Gutiérrez, Chiapas, 1978). Basta releer la lista para constatar que sus nombres, el nombre de todas estas narradoras, o los títulos de sus obras, son sendos filones de la cartografía editorial del siglo XXI. Estas 21 autoras publican de manera impresa y en soporte electrónico; dan entrevistas, tienen seguidores en sus redes sociales, estudian algún posgrado, son editoras, traductoras, profesoras y debaten sobre derechos humanos y, en general, sobre todas las formas de libertad posible. Son plumas y son voces. Entre esas voces y esas plumas, destaca la escritora y periodista Nadia Villafuerte, a quien comencé a leer por la temática de sus narraciones y porque, desde aquel entonces, sospeché que su escritura no responde a una moda ni su idea de literatura tiene ecos de falsedad. Encuentro en ella una congruencia ética y artística que, dicho en pocas palabras, hace que su obra pueda ser leía una y otra vez sin que diga lo mismo.
Nadia Villafuerte nace en el umbral de la década de los años setenta: la vio nacer, en 1978, la ciudad de Tuxtla Gutiérrez, en el biodiverso estado de Chiapas. Allí mismo realizó sus estudios básicos y superiores. Nadia Villafuerte es periodista con estudios en música, pero lo que a ella le agrada destacar es el hecho de haber egresado de la escuela de escritores de la SOGEM. Como muchos de la "generación inexistente", Nadia también fue becaria del FONCA y de la Fundación para las Letras Mexicanas. Ha colaborado en revistas como Letras Libres o la Revista de la Universidad Autónoma de México; ha escrito con regularidad en el portal EsteSur.

Nadia Villafuerte aporta al campo de la narrativa mexicana actual tres obras: dos libros de cuentos y una novela. Hay una plaquete, Preludio (2002, Omega), que ella misma excluye por tratarse de ejercicios literarios ubicados en otros temas, en otro lugar que no es el que pisa con seguridad: la narración de la frontera y la subjetividad que a raíz de ella construyen los sujetos migrantes. En 2005 publica Barcos en Houston con el sello del Consejo Estatal para la Cultura y las Artes de Chiapas, y en 2008 el Fondo Editorial Tierra Adentro respalda la impresión de dos mil ejemplares de iTe gusta el látex, cielo? En 2011, Villafuerte nos sorprende con su primera novela: Por el lado salvaje, publicada en papel por Ediciones B y asequible es soporte electrónico. Sus cuentos y algunos fragmentos de su novela han aparecido en diversas revistas o han sido antologados en publicaciones que buscan integrar un repertorio representativo de la narrativa contemporánea a partir de las voces más consistentes de la generación. Villafuerte forma parte de la antología México20, New Voices, Old Traditions, en cuya edición se involucraron Cristina Rivera Garza, B.D.C. Pierre, Juan Villoro y Guadalupe Nettel (2015). Asimismo, la narradora chiapaneca ha sido considerada autora destacada en varios números de la revista Latin American Literature Today, en la que se han reproducido algunos de sus cuentos o se han publicado entrevistas que escarban en sus ideas literarias, en su intentio autoris.

Actualmente, la narradora de la frontera sur cursa un posgrado en escritura creativa y por esta razón vive en Nueva York. Allí habrá de dar continuidad a 
la carrera que despegó en México, en la Universidad Autónoma de Chiapas y en la Universidad de Ciencias y Artes, del mismo estado.

\section{Engarce para un tríptico de la subjetivación migrante}

En el primer volumen titulado Barcos en Houston, se reúnen quince cuentos; en el segundo, diez. En una y otra colección aparece el cuento "Frontera de sal", que ocupa el lugar décimo cuarto y el tercero en los libros citados, respectivamente. Este espléndido cuento es el mismo que habrá de constituir, en buena medida, la trama-gozne de Por el lado salvaje, la novela. Tanto la narrativa breve como la larga (cuyas partes podrían leerse como si fuesen cuentos integrados), urden sus tramas alrededor de sujetos desplazados, indocumentados, migrantes; sujetos marginados que por ser minoría se vuelven blanco de todo acto discriminatorio. Por el lado salvaje es, también, una heterotopía: se refiere al espacio donde tiene lugar la sordidez llevada más allá de sí misma, donde los umbrales de lo no-habitual, de lo no aceptado o permitido por la sociedad, se tocan con el deseo y la perturbación de esa experiencia deseante y aterradora; es la cara de lo extraordinario, de lo otro que es secreto, pero que al vivirlo rompe el cerco de la intimidad para develar, sin que parezca extraño, la belleza de esa transgresión. También, por supuesto, es un lugar: el Paredón, ese lugar que Villafuerte ha configurado en su narrativa y que constituye ya un elemento claramente identificable de su universo ficcional, de su poética fronteriza y migrante.

Si bien la migración ha sido un tópico en la literatura latinoamericana desde inicios del siglo XIX, la visión de un sujeto migrante heterogéneo, descentrado, enunciado desde su memoria fragmentada, que no desemboca en un espacio armónico de síntesis dialéctica, tal como lo advirtió Antonio Cornejo Polar (1996b), corresponde al siglo XX. Este asunto ha sido de autoría mayoritariamente masculina, pero las hay también femeninas, como la de Nadia Villafuerte, quien ha tenido la inteligencia y la sensibilidad para, alrededor de las voces de sus personajes, trazar geografías de la identidad, es decir, en la escritura de nuestra autora los personajes en desplazamiento van configurando identidades y modos de subjetivación condicionados por las relaciones de poder establecidas con el medio y con los otros. De allí que "el discurso del migrante sea un discurso doble o múltiplemente situado" (Cornejo, 1996b:841), pues en el migrante prevalece la negación a sintetizar las experiencias construidas en "Frontera de sal", engarce para un tríptico de la identidad migrante

La categoría del sujeto migrante tal y como la problematiza Cornejo Polar (1996a) es la que encontramos en la narrativa de Nadia Villafuerte: todo personaje migrante representa un proceso identitario dual; se trata de sujetos fragmentados, conscientes de su heterogeneidad y dispuestos a mantenerse en el espacio liminar de dos mundos. Los de Villafuerte son personajes que hablan desde un doble lugar, desde dos espacios, de allí la fragmentación de su discurso y del sí mismo. El sujeto migrante configurado maneja en su discurso dos esferas de la experiencia que transforman su memoria: su pasado y su presente, y lo hace, en el caso de Lía, la manca que protagoniza la novela, utilizando la tecnología que mejor le funcione en uno y otro caso: la retórica del silencio de su voz o el escándalo incendiario de su cuerpo; la oralidad o la escritura; la escritura o la fotografía. Como muchos de otros personajes villafuertianos, Lía trata de adaptarse a dos sistemas culturales distintos donde el español ya no será el que tenía por correcto, pero que aun así le permitirá ponerse en comunicación con los demás. El migrante no es siempre un sujeto triste, disfórico, es más bien un sujeto melancólico, nostálgico. Migrar, dice Cornejo Polar, es como "nostalgiar" porque

[...] sucede que el migrante nunca deja de serlo del todo, aunque se instale definitivamente en un espacio y lo modifique a su imagen y semejanza, porque siempre tendrá detrás su experiencia fundante y una casi imperturbable capacidad para referir la existencia en relación a [sic] la índole de las estaciones y de las fronteras que hubo de conocer para instalarse en un lugar que probablemente fascina tanto como aterra (Cornejo, 1996a:55). 
Un viejo vagón oxidado en cuyas rendijas altas se amontonan cuatro centroamericanos, dos hombres que se ven por los agujeros de una enorme valla metálica, el camino prolongado y el anuncio en altas "Aquí comienza Guatemala y principia México", una "cámara” formada por dos neumáticos en donde una familia entera cruza el río, dos buses llenos de migrantes deportados, una mujer sentada en las escaleras de un hotel de "mala muerte" en el borde guatemalteco, el mercado itinerante instalado en más de diez kilómetros de línea fronteriza, un oficial de la "migra" tomando cervezas con una prostituta, una cruz solitaria a mitad de la carretera donde murieron dos hermanas antes de iniciar el largo camino hacia el norte del país, los alambres de púas, los cercos, las casetas migratorias son algunas de las instantáneas que la narrativa villafuertiana nos muestra con crudo esplendor.

En sus relatos Villafuerte dota a los migrantes de corporeidad, pero, sobre todo, de voz, como a Lucy, la hondureña del cuento "Navidad en Tapachula", quien se gana la vida prostituyéndose tal como lo hace Elena, protagonista del cuento iTe gustael látex, cielo?, cuyo único deseo, sin importar nada más, "fue salir del muladar donde nació" (Villafuerte, 2008:134); lo mismo ocurre con otra Elena, la "Chica Cosmo", cuyo "destino era Juárez, pero le quedaba claro que bastante había sido acomodarse en Tapachula y no regresar a su pueblo donde, por más turístico que pudiera ser, no acabaría siendo sino una putita más, sin aspiraciones ni glorias" (Villafuerte, 2005:67). Para las mujeres centroamericanas "el trabajo en cualquier bar o burdel estaba garantizado. En ésta como en la otra frontera siempre las preferían extranjeras" (2005:68).

Elena, protagonista de iTe gusta el látex, cielo?, es enganchada por su voluntad y con la complicidad de su propia madre, quien después de escuchar la oferta financiera de la matrona, que en realidad es un travesti, queda conforme con la partida de su hija. Elena prolongará su vida literaria en la novela y será, entonces, un personaje vengativo, depredador, capaz de planear un crimen y disfrutar la caída de su verdugo y enganchador, un travesti con quien establece una relación pasional disfrazada de amistad, dependencia y agradecimiento. En la novela, Elena es vendida por siete mil pesos cuando su cuerpo aún no termina de madurar, cuando es una púber de "tetitas apenas duras". Villafuerte ya había atendido con mayor crudeza esta cuestión en "Cachukas girls" (o "niñas guatemaltecas"), cuento en el que Zambrano transmite a su amigo Cruz la experiencia de un masaje en un barrio de "mala muerte". El "chulo" regente del lugar lleva a Zambrano con "una niña de doce años [con] más huesos que piel en las caderas. Pero sobre todo, los ojos, los ojos aterrados y burlones, desnudos, sin miedo a caer porque ya han caído hasta el fondo" (Villafuerte, 2005:23). Afectado, el hombre cuenta a Cruz sus experiencias sexuales con la niña, su culpa y su frustrado intento de rescatarla. Semejante a esta niña es Amanda, personaje de "Su border": "Tiene doce años pero no importa. A su edad sabe cosas más útiles que ver caricaturas en la tv y jugar en la calle: ahora prefiere hacerlo en un cuarto de motel y se está convirtiendo en una experta en poner y quitar condones" (2005:50). La voz que narra esta experiencia es un adolescente de dieciséis años.

No solo es el sexo y el abuso infantil, también las drogas y el tráfico de personas forman parte de la frontera sur. En "120 kilómetros por hora” Mila y León, dos estudiantes de secundaria enganchan guatemaltecos en "la orilla" y los llevan de regreso con ellos a Tapachula en el Tsuru del papá de León. Las circunstancias los moldean: “¿Cuánto me vas a dar?” pregunta Mila. La negra no trae nada, pero ella se arriesga porque le parece divertido. Esa es su primera experiencia. Después, con León, cobran quinientos pesos por indocumentado. Su próspero negocio de transporte de ilegales termina cuando León cruza la garita entre México y Guatemala en estado alterado y a toda velocidad; los federales les dan alcance. En el Tsuru, dos indocumentadas “aprietan la mandíbula. Sacan un amuleto, contienen la respiración". "Son mis primas", le dice Mila al oficial. "Pues no se parecen en nada", aduce él (Villafuerte, 2005:91). Mila y León acaban en el centro de readaptación juvenil.

En estas ciudades fronterizas la juventud sin expectativas es reclutada por las bandas, como Wenceslao, del cuento "Melancólico", que es deportado de Estados Unidos, "paraíso del que se le expulsó", y termina incorporado a las filas de La mara. Son varios los perso- 
najes que recurren a la protección de sectas o grupos delincuenciales, como la protagonista de "Yonqui", quien, ante la violencia intrafamiliar que padece, pues su hermano abusa de ella, toma cartas en el asunto y se hace justicia por su propia mano después de integrarse a una banda: "los reté, pónganme a prueba, pendejos, y le quité la fusca al Diablo y apunté hacia la calle y le disparé a un punto negro que vi en el horizonte" (Villafuerte, 2005:38).

Sirva la recuperación de las fabulaciones anteriores para conocer el modo en que Villafuerte estiliza el borramiento, la pérdida y la adquisición de distintos modos de subjetivación durante el proceso de desplazamiento forzado. Nada se anula, todo se mezcla y así crece dando origen a un sujeto en sí mismo multicultural, diverso, complejo y verdaderamente heterogéneo porque se piensa siempre en dos espacios, al menos. Villafuerte, bordando finas relaciones interdiscursivas con la crónica periodística, elabora y expresa un discurso testimonial en el que la voz está signada no solo por la denuncia social o política, sino por una narratividad en la que la frontera se enuncia con atinada retórica y alcanza estatuto poético, simbólico. En esta narrativa el tema de la frontera se coloca en el intersticio de la ficción y la no-ficción. Los relatos no pueden comprenderse sin la idea de violencia, sin el conjunto de estadísticas que indica a penas la cantidad de indocumentados que no logran cruzar "al otro lado", o sin la fotografía de abusos que acepta el sujeto migrante cuando ha logrado su cometido: estar en territorio de otros vuelve ajeno todo; conduce no "a una suerte de", sino a una clara y tremenda despersonalización y anulación de la identidad en tanto un único modo de subjetivación; para el migrante el trabajo de constituirse en sujeto es siempre doble: atesora su identidad de origen y lucha por adquirir una nueva que abra o facilite su comunicación con los otros. En esta línea interpretativa es que Alejandro de la Garza ubica la obra de Villafuerte:

[su] prosa respira, palpita, se agita con vida propia a cada párrafo; atraen su tono aforístico y sentencioso, su evasión del lugar común, la búsqueda de metáforas propias, la vibrante fuerza narrativa expresada por todos los personajes, la tensión pulsante de su adjetivación. Una escritura con estoica o cínica forma de relatar y aceptar el mundo como es: violento, injusto, desesperanzado, criminal" (Garza, 2011:s/p).

Algunas veces, el viaje hacia Estados Unidos no es un viaje en línea recta, sino que se hace a pequeños saltos, de poblado en poblado "aunque siempre tengas que empezar y va de nuez" (Villafuerte, 2005:107), como se obliga a hacerlo el narrador autodiegético de "Barcos en Houston". Otras veces, el viaje hacia el norte se hace por autobús, con documentos falsos. Entonces, lo más importante para un indocumentado centroamericano en tierra mexicana es mantener la boca cerrada, pues "siempre es un inconveniente lo del acento. Porque por lo demás, el mismo color, la estatura, el rostro de jodidez inconfundible" (2005:70). Pero el medio de transporte más accesible a los indocumentados centroamericanos es el tren. A los centroamericanos "el maquinista los trae como moscas pegadas a los oxidados vagones" (2005:78). Las consecuencias de utilizar este medio son muchas veces trágicas, así le ocurre a Ima del cuento "Cascarita", quien pierde las piernas al saltar del tren en una sorpresiva inspección migratoria.

La experiencia de Ima y su hermana Carmen muestra los abusos que padecen los migrantes centroamericanos al cruzar el territorio mexicano. Ellos saben que el trayecto hacia la frontera norte está colmado de "traileros mierdas. Polleros abusivos. Cuotas imposibles. Matones" (Villafuerte, 2005:98). En una hipotética entrevista, para el reportaje "OperativosMuerte", el personaje Carmen cuenta: "durante dos días nos escondimos, huimos de los policías mexicanos que nos robaron y nos querían abusar... Ellos tuvieron la culpa, nosotras sólo queríamos llegar a Estados Unidos, ellos ya nos habían robado antes poco menos de mil dólares" (2005:76-77). Pero los abusos no vienen solo de policías mexicanos, el crimen organizado también está a la caza de migrantes. En un artículo respecto al tema, Óscar Martínez (2009) señala que las bandas de la zona, muchas de las cuales trabajan para Los Zetas, cobran a los migrantes por abordar el tren y a los coyotes por transportar personas, castigan 
a quienes no pagan y secuestran a los ilegales que no viajan con alguno de sus protegidos.

Además de esos abusos, los migrantes se enfrentan a la frontera cultural, al rechazo y menosprecio de los mexicanos. Cuando leemos el diálogo interno de un personaje femenino del cuento "Yésira" podemos percatarnos de dicho rechazo:

Es fuereño. De eso ni duda. Por la ese arrastrada. Guatemalteco. Porque de acá, no. Nos están invadiendo. Vas a las cosechas y ahí están. Vas a la fila de tráileres y ahí se esconden. Se asoman por la estación y por la noche rondan. Ni se diga en la zona, atascada de negras dispuestas a soportar cualquier cosa con tal de conseguir billetes. Nos pareemos mucho, es cierto. Tenemos casi las mismas facciones, el mismo brillo grasoso en la cara. Alguna mueca. Pero si algo los distingue es el pánico con el que ven, hablan, caminan. Eso ha de ser. Huyen... (Villafuerte, 2008:41).

La lengua es, también, otra frontera. Si bien el español es la lengua franca en los países fronterizos del sur, la forma de emplearlo implica una división y una diferencia entre aquellos que lo enuncian: acento, entonación, ritmo, usos coloquiales, multiplicidad semántica y préstamos lingüísticos son elaborados con maestría por la autora chiapaneca porque ha sido capaz, a semejanza de un fotógrafo, de mostrarnos "la cruda belleza de la miseria" (Villafuerte, 2005:126), y ha logrado que sus lectores la aprecien también, aunque en ella primen el horror y el error.

La discriminación se expresa con tono satírico e irónico: Key, la protagonista de “Cajita feliz", es hondureña y tiene por marido a un mexicano que encuentra gracioso burlarse de ella: "es fácil imaginarse México, todo el mundo ha tomado un trago de tequila y visto mariachis, pero iHonduras?" (Villafuerte, 2008:93). En el imaginario norteamericano, México es Centroamérica y todos los migrantes, mexicanos. La diferencia es lo de menos, son mano de obra barata, sirvientes. Pero para el mexicano sí hay diferencia. Estar un poco más cerca del asediado centro los lleva a asumir una actitud semejante a la de los ladinos durante la Colonia, aquellos abusaban de los indios, estos de los centroamericanos. La actitud revanchista contra el más débil es evidente.

La frontera norte es el objetivo de todos los migrantes centroamericanos, aunque la frontera sur entorpezca su tránsito; pero esta es solo una vaga idea que implica un mejor estilo de vida y la posibilidad de acceder al american dream. Sin embargo, la otra frontera, la zona sur que imaginariamente divide México de Centroamérica a través de intrincados caminos acuáticos, férreos y montañosos que implican, además de las inclemencias del territorio y el clima, otros peligros más avasallantes para los transeúntes, es la que los detiene. Nadia Villafuerte explora con acierto y una mirada crítica, descarnada y efectiva los conflictos vividos por esos personajes que recorren, las más de las veces, esa suerte de agujero negro, de abismo, que es el territorio mexicano. Así, la frontera con el vecino país del norte es un lugar lejano, una representación ficticia, un no-lugar inalcanzable. México es ahora el lugar destino, donde muchos de los centroamericanos permanecen en las condiciones más inmisericordes que puedan presentarse.

En suma, me parece que Nadia Villafuerte avanza como autora al publicar su novela. Por el lado salvaje es formalmente ambiciosa porque no solo mantiene la discursividad híbrida de la narrativa periodística y la narrativa ficcional que ya le reconocíamos en los cuentos, sino que aquí además de la historia, como toda buena novela, la bisagra está en la configuración de los personajes. Los personajes de Por el lado salvaje son huidizos, caminan en el borde y se desbordan, caminan por el filo, ese doble filo, y solo terminan cortándose, son personajes en fuga de sí mismos porque están hartos de desdoblar, de multiplicar su identidad, de buscarla y perderla como si estuvieran emulando a Sísifo.

Lía es la protagonista de Por el lado salvaje. Es una mujer manca, es decir, su cuerpo experimenta uno de los más altos grados de violencia: la mutilación. Pero la narración no va hacia el porqué es manca, sino que indaga en la manera en que ella ha sido capaz de desdibujar para sí y para los demás esa característica de su cuerpo. De ella sabemos que nació en el mar muerto de Paredón, un pueblo que huele a sal y a camarón seco, ese lugar es, en pocas palabras, una frontera de sal. 
Por ellado salvaje es una novela cuya temática, como he insistido, está en consonancia con los libros de cuentos de Villafuerte: Lía emprende un viaje desde México, particularmente desde la frontera sur con Guatemala, hasta Honduras y Nicaragua; estando en Centroamérica es conminada a viajar al norte de México y llega a Tijuana para incorporarse como trabajadora en un burdel. El tema lo conocemos bien por los cuentos, pero el estilo de la novela es otro: aquí la multiplicidad es abrumadora porque sus intervenciones son vertiginosas. Cada uno de los personajes que protagoniza alguno de los capitulillos de la novela (o los fragmentos que los integran), narra su propia historia; es decir, se les dota de voz para que sean ellos mismos quienes expresen su subjetividad, de allí el parentesco con las escrituras del yo: la confesión, el testimonio y la autobiografía. En este punto conviene recuperar la síntesis que Ana Luisa Coulon elabora de la novela:

\begin{abstract}
Los relatos [capitulillos o fragmentos], cargados de una buena dosis de violencia visual, quedan detenidos en el tiempo como fotografías, similitud que sirve para resaltar un conflicto que está paralizado, sin posibilidades de cambio. También evoca el fotomontaje, ya que cada personaje, con su respectiva visión, se replica, pero bajo la mirada del otro. Aunque algunos capítulos están a cargo de un narrador omnisciente, en todos se exploran distintos aspectos y puntos de vista sobre los efectos de la violencia, la que se vuelve más alucinante en el caso de Lía, por la opresión que ha padecido desde niña (Coulon, 2014:86).
\end{abstract}

El lector conoce a Lía cuando tiene escasamente doce años, pero sabe por ella que desde más niña vivió rodeada de violencia, al grado de considerar que es esa la única forma en que habrá de vivir la vida. El viaje que emprende hacia Honduras es un escape y lo hace al lado de Genaro, un biólogo travesti que la humilla, la intercambia sexualmente con sus amigos, sobre todo con Barden, un europeo que viaja a Centroamérica para hacer periodismo fotográfico en Nicaragua y, aunque no lo reconozca, para huir de los señalamientos de pornógrafo que había en su contra a causa del tipo de fotografías que solía tomar, entre otros niños, a una de sus hijas. Genaro (o Glenda) y Barden cumplen el papel de verdugos de Lía, pero será el fotógrafo quien establezca con ella la relación más perversa: la mirada de Barden sobre el muñón de Lía mientras exploran distintas posiciones sexuales será la mayor humillación que ella experimente. En silencio ahoga la verdadera pasión de Lía: el deseo de asesinarlo, de destruirlo. No lo hace; sigue con él hasta que es enviada al prostíbulo de Tijuana.

El cuerpo de Lía es sometido por ella y por los otros a terribles acciones de violencia. Es violada, es explotada como si fuera esclava, es obligada a abortar, a prostituirse teniendo como proxeneta a Draco, pero siendo a la vez la pieza clave para que Barden y Eduardo Rodríguez recuperen y negocien con los negativos de unas fotografías que dan cuenta de las torturas y asesinatos ordenados por el dictador Somoza García en la Nicaragua de los años setenta. La trama está llena de subtextos e intertextos históricos y literarios bien manejados que logran mantener la tensión narrativa a lo largo de todas las páginas de la novela, sin embargo lo verdaderamente atractivo es la respuesta de supervivencia que Lía tiene ante tanta adversidad. Y no, no hay final feliz. Como Lía viajó de Honduras a Tijuana con documentos falsos y otro nombre (nombre falso como el de Ricardo Piglia), cuando logra escapar de Draco con la ayuda de Rodríguez, llega a Monterrey y se descubre extranjera en su propio país, a punto de ser deportada. Será la visión de mundo que tiene Lía la que predomine en la narración que cierra la novela, con lo cual se muestra la gran capacidad de resiliencia que tiene aunque sepamos que no puede evitar caer en el abismo y comenzará de nuevo a subir la cima empujando una gran roca.

\section{Atisbos de una poética fronteriza desde la perspectiva del sujeto migrante}

En tanto género discursivo, la literatura posee una dimensión ético-política de los asuntos que ha tratado a lo largo de sus páginas. Desde las expresiones más antiguas, hasta algunas de las más logradas en los albores 
del siglo XXI, son muchos los autores (y las voces) que han reiterado su compromiso social con la época y las circunstancias históricas que les han tocado vivir. Herederos o influidos por esta o aquella episteme, de alguna manera prestan su voz a quienes carecen de ella, sea a través de la figura del simple observador, sea mediante la configuración de un personaje que experimenta el crisol más variado de las escrituras del sí donde el centro es ocupado por la memoria. La enunciación testimonial, la crónica, son géneros discursivos que buscan expresar problemas actuales, vigentes; esto sin perder nunca de vista la estilización que le es propia a la producción artístico-verbal.

Sin duda, uno de esos grandes temas que a todos nos convoca es el de las fronteras y las migraciones; en el caso de América Latina la frontera siempre fue la del norte, la que separa la República Mexicana de los Estados Unidos de Norteamérica; hacia abajo todas eran consideradas fronteras de paso, de tránsito; aquella lo es de destino, de allí su importancia. La noción de frontera, lo sabemos todos, no es solo espacial ni política, es también simbólica. Quiasmo, diastema, no-lugar, diáspora convertida en vértice para algunos y pivote para otros. Punto de encuentro y desencuentro donde la línea divisoria es muy delgada, la frontera entre la vida y la muerte es la misma. Cruzar la frontera es, de alguna manera, "entrar en el mal"; en aras de un mejoramiento, en la búsqueda de una mayor calidad de vida y muy utópicamente de un atisbo de igualdad; aquel que abandona su lugar de origen acepta y se resigna a un mal apriori, pues el mal, como afirma sugerentemente García de la Sienra, "se sitúa en el sujeto, o lo que es lo mismo, en los procesos de formación subjetiva emanados de la confrontación incesante con los límites que, más allá de los saberes establecidos, conforman el espacio de lo humano" (2011:33). Este espacio, a la vez humano y ajeno, es el motivo que rige las distintas configuraciones de las mujeres migrantes de Nadia Villafuerte.

La experiencia que resulta de cruzar el territorio fronterizo configura a un sujeto muy complejo: se trata de un sujeto que es al mismo tiempo individual y colectivo: su partida es más bien una especie de expulsión y se ha tenido que valer de otros para emprender el viaje.
El migrante se desplaza en grupo, en pareja cuando menos, pero sabe que en realidad viaja solo. Al margen de las razones económicas o políticas que empujan a los individuos a emprender el camino hacia la frontera, es su experiencia personal y la mutabilidad de su subjetividad la que salta y asalta a los lectores: la separación de lo propio para ir a conquistar lo ajeno —en muchas ocasiones imperceptible al ojo humano- se vive como una ruptura, como un abandono del sitio originario para cruzar ese otro límite - el del deseo, la suerte y la esperanza- que el sujeto interioriza a tal grado que es capaz de transformarse hasta desaparecer durante su tránsito hacia "el otro lado". El paisaje es otro, el lenguaje es distinto, la comida tiene otro sabor, la complicidad deja de existir; la nueva geografía se presenta como un medio inclemente e inhóspito. No hay en este desplazamiento unidad, la multiplicidad flota en cada rostro, en cada acento, en cada mirada huidiza que intenta esconderse eintenta, también, pasar desapercibida. Despersonalizarse, no ser, desaparecer, dejar de ser sujeto y volverse objeto de una muda enunciación que permita llegar "al otro lado", a Estados Unidos de Norteamérica, hasta aquella frontera, porque la de abajo, la del sur, es la misma en ambos lados de la sierra y el Suchiate.

La narrativa de Nadia Villafuerte tiene un asidero más allá de la temática y más allá de la referencia geográfica, es decir, de los marcadores de época; sus cuentos y su novela logran instalarse en la porosidad de un espacio que sigilosamente funde y confunde ética y estética; es un espacio-tiempo que nos atraviesa a todos porque nos lleva con la mirada del que es testigo a experimentar, de manera aparentemente ajena y distante, el malestar y la violencia que sufren sus personajes para después envolvernos con elocuencia poético-narrativa, por un acto casi de sublimación, en la visión que nos hace disfrutar justo eso que podríamos convenir en llamar la belleza del lado salvaje de la vida. En este sentido, la novela es terrible, inquietante porque mantiene al lector en los umbrales de las relaciones de deseo y las de poder y sometimiento. La voz narrativa, las muchas voces narrativas de Villafuerte, llevan al lector a ser parte de esa realidad cruda y atractiva del mal, como si el proceso de estilización lograra iluminar ese abismante 
terreno del malestar al grado de desaparecerlo. No es así; de inmediato, esas mismas voces acentúan lo terrible de los actos y nos alertan del peligro de creerlo todo, de aceptarlo todo, de normalizarlo, de ser parte de ello e incluso de consentirlo, de consumirlo siquiera con la mirada, como testigos cómplices del mal.

Podría decirse que el presente literario de la narrativa de Nadia Villafuerte, ese espacio desde donde escribe, está atravesado por el sesgo de la memoria, del malestar, del desarraigo, de la violencia, de la migración, y dentro de esta existe una muy marcada nostalgia por la frontera sur, por aquello a que dio origen el viaje forzado. "Nadia confiesa ser autora con raíces muy profundas en un único lugar, comprometida a contar historias de los migrantes que cruzan la frontera sur de México y van hacia el norte en busca de una vida mejor, a pesar de todas las dificultades que se encuentren en su camino" (Dixon, 2017).

Los cuentos y la novela han consolidado, en el universo narrativo que integran, la doble y escurridiza mirada de personajes que son, a un tiempo, víctima y victimario. El discurso narrativo se sitúa en el instante fugaz que da pie al pasado y al futuro: las narraciones vienen y van de una frontera a otra, de un umbral a otro, de un límite a otro, de una laguna a otra, de un mar a otro. Como las novelas cortas de los contemporáneos, las de Nadia Villafuerte también son narraciones y descripciones que alcanzan la iconicidad de las fotografías, son postales, son tomas cinematográficas. Laten en su narrativa la crónica, el reportaje y el documental como formas genérico-discursivas que dan vitalidad y verosimilitud a las historias ficcionales mediante una voz que mucho tiene de enunciación testimonial.

Contrario a lo que pudiera pensarse, los personajes de Nadia Villafuerte no huyen tanto de la violencia sino que, sin ignorarlo por completo, a ella se dirigen, sobre todo los personajes femeninos. El motivo para desear la frontera es, casi siempre, la pobreza. El motivo del viaje forzado puede ser la búsqueda de trabajo estable, reconocido como profesional y remunerado en esos términos, pero lo que se consigue es otra cosa: los personajes de esta autora se instalan en ese otro lugar realizando trabajo forzado que se disfraza de diversión, de gozo; aquí la explotación, el abuso y la violencia son los elementos que acentúan el fracaso del sueño del migrante. En este punto, la intencionalidad discursiva de Villafuerte se emparenta con los universos figurales de otras autoras de la generación contigua: la de los ochenta. Me refiero específicamente a Valeria Luiselli en su Desierto sonoro y a Fernanda Melchor en su Temporada de huracanes.

La trilogía fronteriza de la sal, como cabría denominar a la constelación que forman los dos libros de cuentos y la novela escritos por Nadia Villafuerte, no solo traza sino que corporiza la subjetividad de las mujeres migrantes centroamericanas. A diferencia de otras narrativas, la de ella no solo hunde su pluma en el desarraigo, la incertidumbre y los avatares de los desplazados sin documentos, sino que sabe crear una voz y una perspectiva femeninas que hurgan en aquello otro que también constituye a los migrantes y que, quizá por un inconsciente acto de romantización, suele dejarse de lado. Me refiero a la perversidad y la normalización de la violación de eso que llamamos el Estado de derecho. Y es que lo terrible en la escritura de Villafuerte no es la violencia en sí misma, sino ese doble filo en medio del cual coloca al lector: el doble filo del arte es situarnos frente a los actos de abuso sin que advirtamos, de inmediato, el perverso juego de la normalización que siempre estamos bordeando. La pornografía, la pedofilia, la xenofobia, la violencia de género, la discriminación son formas de destrucción humana que al pasar por ese doble filo del arte se distancian de los parámetros morales del afuera para fijarse justo en el filo, que por serlo corta y hace sangrar desde el otro lado de la línea, esa que ya no está en el objeto artístico, pero que inevitable y afortunadamente vive en la lectura, actividad imposible de realizar fuera de nuestra sombra: la lectura es situada, por eso es que la subjetividad de los personajes es, en gran medida, nuestra.

En este tríptico de la frontera de sal, casi todos los personajes pertenecen al grupo no de los viajeros o turistas con visa y pasaporte; tampoco cabe para ellos la esfera de la diáspora, pertenecen, como he dicho, a los migrantes indocumentados sin sentido de comunidad o grupo. Son sujetos, hombres y mujeres, 
que viven en dos mundos: el que dejan y el que quieren conquistar. Ya no están en su aquí, y nunca terminan de llegar al allá. Están escindidos, fragmentados, por eso el migrante, como señala Cornejo Polar, es quien mejor representa la heterogeneidad moderna y se instala en un nostalgiar permanente.

Los migrantes son sujetos entre dos mundos (inbetween). Su nostalgia no es propiamente un estado de ánimo, es el temple con que viven. El migrante, como se sabe, abandona un lugar y llega a otro siempre con la idea de volver para mejorar las condiciones que aquí dejó, o con la idea de adaptarse a lo que allá encontrará. La del migrante es, entonces, una identidad escindida, sincopada, cortada y unida por los extremos: aquí y allá son márgenes puenteados por el mismo sujeto que sin advertirlo los repele.

El problema de la identidad migrante para la narrativa radica en el desplazamiento; el viaje es a la vez geográfico e interior, es decir, una forma de Bildung [sic] de movimiento espacial entre culturas. La ruptura del lugar de origen y el contacto con otras culturas actualiza, o pone en cuestión, muchos aspectos de la identidad que contribuyen a construir la personalidad del individuo y la imagen que tiene de sí mismo. Para el migrante indocumentado, convertido en un ser invisible y oficialmente inexistente, la crisis de identidad que resulta del cruce clandestino tiende a ser aún más palpable, porque, como afirma SchmithWelle, "el miedo de perder la identidad o integridad de un migrante ilegal es un miedo concreto, histórico, igual que el miedo de los exiliados y torturados que reafirman su subjetividad mediante la memoria de una dictadura en sus pesadillas". A la vez, el migrante literario cartografía, a través de su mirada bifocal o visión estereoscópica, las diferencias que observa en el cruce de fronteras tanto en un sentido literal como en un sentido metafórico (Olsso, 2016:18).

Vivir en la frontera, pasarla, viajar a través de ella, coloca a los personajes en un vasto espacio donde los valores sociales, bioculturales, políticos, económicos e ideológicos se tensan en una interacción que no siempre es dialógica, ni plural, ni libre. Por eso la insistencia en señalar que la línea fronteriza es como ese doble filo del arte: tira de un lado y del otro. Hunde a los personajes en la esperanza o en la nostalgia, más en esta que en aquella, por eso es que aunque vivan al día, jamás se sitúan en el presente, más bien están en el pasado; su pasado es su presente. El discurso del migrante se construye desde una subjetividad dislocada y, en este sentido, su memoria no es otra que la del desarraigo y la nostalgia.

\section{Consideraciones finales}

Recorrer la narrativa de Nadia Villafuerte permite conocer un universo narrativo complejo no solo por su composición formal, la actualidad de los temas y la perspectiva de enunciación, sino porque hay en todo ello la definición de un estilo que es, a su vez, manifestación de una postura autoral. El énfasis puesto en las configuraciones de los personajes permite reconocer distintas representaciones culturales de la migración: no se trata solo de ver en el sujeto migrante al desplazado, a la minoría, al desprotegido, al subalterno; se trata también de reconocer su capacidad y derecho a experimentar dos visiones de mundo, a vivir en dos mundos sin el deseo de querer sustituir uno por el otro, o a sintetizar dos mundos en uno solo. En esto radica el acierto estilístico de Villafuerte: elegir, de manera precisa, el lugar de enunciación para sus personajes; filtrar entre las distintas voces la visión autoral sobre el problema migratorio en la frontera sur, que como periodista Villafuerte conoce bien, al grado de apropiárselo sin disminuirlo con focalizaciones planas o carentes de visión crítica. La ironía y el sarcasmo funcionan en este nivel discursivo como elementos fundamentales de verosimilitud e incluso como fuentes de empatía con el lector.

Leer narrativa de Villafuerte teniendo como trasfondo las nociones de heterogeneidad y sujeto migrante de Antonio Cornejo Polar abre el horizonte de la lectura hacia un espacio interdiscursivo, pero sobre todo señala, de entrada, la posibilidad de reconocer en el sujeto migrante no la fusión de culturas, sino la coexistencia de dos mundos que ajenos entre 
sí se comunican, dialogan y dan forma e identidad particulares a los sujetos fronterizos.

\section{Referencias}

Cornejo Polar, Antonio (1996a). "Tradición migrante e intertextualidad multicultural: el caso de Arguedas". En CELEHIS. Revista del Centro de Letras Hispanoamericanas, 1(6-7-8), 45-56.

Cornejo Polar, Antonio (1996b). "Una heterogeneidad no dialéctica: sujeto y discurso migrante en el Perú moderno". En Revista Iberoamericana, LXII(176-177), juliodiciembre, 837-844.

Coulon, Ana Luisa (2014). "Sobre la extrema violencia en la vida cotidiana: Por el lado salvaje, de Naida Villafuerte". En Romance Notes, (54), 85-92.

Dixon, Arthur (2017) "Un inmigrante nunca termina de llegar: una entrevista a Nadia Villafuerte". En Latin American Literature Today. Norman, OK: University of Oklahoma. Disponible en http://www. latinamericanliteraturetoday.org/es/2017/january/ un-migrante-nunca-termina-de-llegar-una-entrevistanadia-villafuerte-por-arthur-dixon (consultado el 30 de noviembre de 2019).

García de la Sienra, Rodrigo (2011). "Frontera y estética de la desaparición. Infrapolítica, verdad, archivo y soberanía". En Norma Angélica Cuevas Velasco y Raquel
Velasco González (coord.), El norte y el sur de México en la diversidad de su literatura. México: Juan Pablos Editor.

Garza, Alejandro de la (2011). "De lo canalla y la alteridad". En Nexos, 1 de octubre. Disponible en https:// www.nexos.com.mx/?p=14523 (consultado el 15 de noviembre de 2019).

Martínez, Oscar (2009). "Migración centroamericana, dominio zeta". En Proceso (1714), 6 de septiembre.

Mesa, Jaime (2016). "100 protagonistas de la generación inexistente". En Literal. Latin American Voices (20), abril. Disponible en https://literalmagazine.com/lalista-de-la-generacion-inexistente/ (consultado el 20 de abril de 2020).

Olsson, Fredrik (2016). "Me voy pal norte". La configuración del sujeto migrante indocumentado en ocho novelas hispanoamericanas actuales (1992-2009). Sevilla: Universidad de Sevilla.

Rivera Garza, Cristina, D.B.C. Pierre, Juan Villoro y Guadalupe Nettel (eds.) (2015). México20. New Voices, Old Traditions. Londres: Pushkin Press.

Villafuerte, Nadia (2005). Barcos en Houston. Tuxtla Gutiérrez: Consejo Estatal para la Cultura y las Artes de Chiapas.

Villafuerte, Nadia (2008). ¿Te gusta el látex, cielo? México: Tierra Adentro.

Villafuerte, Nadia (2011) Por el lado salvaje. México: Ediciones B. 